\title{
Evaluation of Gartland Type-III Closed Supracondylar Fracture of Humerus in Children Treated by Lateral Percutaneous K-Wires under C-Arm Guidance
}

\author{
Md. Insanul Alam*1, Sheikh Firoj Kabir², Md. Faridul Islam³ , Md Ismail Hossain, \\ Md Omar Faruque ${ }^{5}$, Hosne Ara ${ }^{6}$, Md. Rezaul Alam ${ }^{7}$
}

\begin{abstract}
Introduction: This study has been designed to evaluate the success rate of closed reduction and stabilization by two lateral parallel percutaneous $K$-wires with the help of $C$-arm in the management of Gartland type-III closed supracondylar fracture of humerus in children. Materials and Methods: A prospective quasi experimental study was conducted from January 2015 to December 2016 in NITOR. A total of 30 patients of Gartland type-III closed supracondylar fracture of humerus in children presenting between ages 3-12 years. Informed written consent was taken from patient's guardian. Regular follow up was targeted for at least 6 month's. Result was evaluated according to Flynn's grading. Results: Mean age was $6.85 \pm 2.37$ years, number of patients ware 30, Male patients were more affected $22(73.33 \%)$ than female $8(26.67 \%)$, left side patients were more affected. Mean loss of elbow flexion was 9.53 degrees, mean loss of carrying angle was 8.5 degrees. Complications included four (13.33\%) cases of pin tract infection, four $(13.33 \%)$ cases of fracture blister, one (3.33\%) case of median nerve palsy, two (6.66\%) cases of inadequate pin fixation at first attempt. There were six excellent (20\%), eighteen good (60\%), three (10\%) fair and three (10\%) poor results according to Flynn's grading. The overall $90 \%$ satisfactory result and rest $10 \%$ unsatisfactory result. Conclusion: Closed reduction and stabilization by two lateral parallel percutaneous K-wires is a better method for treatment of Gartland type-III closed supracondylar fracture in children.
\end{abstract}

Key words: Evaluation of Gartland Type-III, Supracondylar Fracture of Humerus.

Number of Tables: 08; Number of References: 20; Number of Correspondence: 07.

*1. Corresponding Author:

Dr. Md. Insanul Alam, MBBS, MS (Ortho)

Assistant Professor (cc), Department of Orthopedics Medical College for Women \& Hospital, Uttara, Dhaka. Email: insanulalam78@gmail.com Mob: 01914-385000

2. Prof Dr. Sheikh Firoj Kabir, Major (Retd), MBBS, MCPS,FCPS(Surgery),FRCS(Glassgow),FACS(USA) Principal \& Head, Department of Surgery Medical College for Women \& Hospital, Uttara, Dhaka.

3. Dr. Md. Faridul Islam, MBBS, MS (Ortho) Registrar, Department of Orthopedics Abdul Malek Ukil Medical College, Noakhali.

4. Dr. Md Ismail Hossain, MS Ortho Junior Consultant 250 beded Distric Hospital, Chapainawabganj.

5. Dr. Md Omar Faruque, MBBS, MS (Ortho) Junior Consultant, Department of Orthopedics NITOR, Dhaka.

6. Dr. Hosne Ara, MBBS, DGO (Gynae \& Obs) Junior Consultant, Department of Gynaecology \& Obstetrics 250 Bed TB Hospital, Shyamoli, Dhaka.

7. Dr. Md. Rezaul Alam MBBS, FCPS (Surgery)

Assistant Professor (cc), Department of Surgery Medical College for Women \& Hospital, Uttara, Dhaka.
Introduction:

In children supracondylar fracture of humerus is the commonest fracture. This fracture is common in the 1st decade of life due to ligament laxity. The fracture line is generally transverse; results from a fall on the outstretched hand, and should always be suspected,if child complains of pain in the elbow after such an injury. These injuries can also occur due to fall from height and assault by any mean ${ }^{1}$. The most popular method of treating the severely displaced unstable supracondylar fracture was described by Dunlop. Other methods are modifications of Dunlop's, employing skeletal traction through the olecranon, pulling horizontally or vertically. Traction methods need approximately three weeks of hospitalization. Treatment in traction usually loss of carrying angle. Treatment by open reduction and internal fixation is not popular because the method has some complications such as limitation of motion ${ }^{2}$. The extension type of supracondylar fracture of the humerus is the most common, occurring in $95 \%$ of cases. About one-third show little or no displacement and in these treatment is simple. The remainder is associated with varying degrees of major displacement which is difficult to treat. For most cases, manipulative reduction and immobilisation in a plaster slab is the procedure of choice, but early and late complications can occur. Cubitus varus is the commonest of the late complications. When the elbow is in extension, both the extensor and the flexor muscles are mechanically neutralized and the carrying angle can be judged accurately, clinically and radiologically. In recent study it is postulated that a method of manipulative 
reduction, immobilization and fixation using a U-shaped plaster slab with the elbow in full extension would allow the displaced fragment to be easily reduced and retained after reduction ${ }^{3}$. There are various modalities of treatment adviced for the management of Gartland type III closed supracondylar fracture of humerus. At present closed reduction and percutaneous pin fixation is most widely accepted treatment method for displaced supracondylar fracture but controversy persists regarding the optimal pin fixation technique. The purpose of the study was to compare the stability and risk of ulnar nerve injury treated by lateral entry pin fixation with that of medial and lateral pin fixation for Gartland type III supracondylar fracture ${ }^{4}$. In third and fourth century, Hippocrates described supracondylar fractures (SCF) of the humerus in children ${ }^{5}$. In 1826, Astley Cooper and in 1921, Robert Jones recommended treating these fractures using the collar and cuff technique cited in English-language literature ${ }^{6}$. In 1965, El-Sharkawi and Fattah described the treatment of supracondylar fractures in extension: in one of these a plaster cast was used $^{7}$. Devkota et al. 2008, studied 102 displaced supracondylar fractures of humerus, aged between one and half to 13 years. They were treated closed reduction percutaneous Kirschner wire fixation under C-arm fluoroscopy. Seventy nine patients were treated by cross $\mathrm{K}$-wires and in twenty three cases lateral two K-wires were put. All patients were followed upto 14th week postoperatively ${ }^{8}$. At the lower end, four secondary centres appear. There is one for capitulum and lateral ridge of the trochlea at 2 nd year, one for medial epicondyle at 5 th year, the remainder of the trochlea at the 12th year and the lateral epicondyle at the 13th year. The medial epicondyle remains as a separate centre, separated by a downward projection of the shaft from the other three which fuse together. Union with the shaft occurs at about 16th year. (Skaggs and Flynn, 2015) ${ }^{9}$.

This study designed to evaluate how much effective the procedure that is closed reduction and stabilization by two lateral parallel percutaneous ' $\mathrm{K}$ '-wires for treatment ofGartland type-III closed supracondylar fracture of humerus in children.

\section{Materials and Methods:}

This prospective quasi experimental study was conducted from January 2015 to December 2016 (24months) at National Institute of Traumatology and Orthopedic Rehabilitation (NITOR), Dhaka. All patients suffering from closed supracondylar fracture of humerus in children. Each Gartland type-III closed Supracondylar Fracture of humerus among supracondylar Fracture in children attended at emergency, outpatient department and admitted in NITOR from January 2015 to December 2016.Purposive sampling (non-randomized) according to availability of the patient and strictly considering the inclusion and exclusion criteria Inclusion criteria: Age: between 3 to 12 years, Sex: Both sexes, Type III supracodylar fracture of humerus in children, Those presented within 5 days after injury, Closed fracture, Extention type. Exclusion criteria: Open fractures, Pathological fractures, Age before 3 and after 12 years. Flexion type, Type III fracture with comartment syndrome, late presentation after 5 days. $1.8 \mathrm{~mm}$ or $2 \mathrm{~mm} \mathrm{~K}$ wires selected according to the age. First wire started from the tip of lateral epicondyle directed across the fracture towards the medial cortex in $50^{\circ}$ to $60^{\circ}$ angle. $\mathrm{K}$ wire position in lateral view confirmed. 2nd wire passed $1 \mathrm{~cm}$ below the first $\mathrm{K}$ wire and passed exactly parallel to it, crossing the olecranon fossa and having 4 cortical purchase. Elbow extended and rotated, stability of fracture assessed under C-Arm. If we feel like cortial purchases are inadequate, remove wire and again we can put 2 nd wire in similar fashion, between the parallel wires. All wires cut after bending, outside the skin and supported by LABS.

\section{Results:}

The results were assessed on the basis of Flynn's criteria (Flynn, et al., 1974). Table-1 shows that are The youngest patient in our series is 3 years old and the oldest is 12 years. Majority were in 5-8 years. Among 30 patients mean age was 6.85 years with $\mathrm{SD}= \pm 2.37$ years. In the present series, maximum patients were male $22(73.3 \%)$ and 8 (26.7\%) patients were female. Male female ratio 2.75:1. Male patients were predominant in this study. The results are shown in table-II. In the present series, $19(63.3 \%)$ with left sided supracondylar fracture of humerus and 11(36.7\%) presented with right sided supacondylar fracture of humerus. The results are shown in Table-III. Out of 30 cases 15 $(50 \%)$ cases gave history of fall from tree, $6(20 \%)$ cases gave history of fall from bed, $4(13.3 \%)$ cases gave history of fall during playing, $5(16.7 \%)$ cases gave history of RTA due to fall from bicycle.

Table-I: Age, Sex, Side and Causes distribution of the participants $(n=30)$.

\begin{tabular}{|c|c|c|c|c|}
\hline & $\begin{array}{l}\text { Group of } \\
\text { variable }\end{array}$ & $\begin{array}{l}\text { No of } \\
\text { Patient }\end{array}$ & $\begin{array}{c}\text { Percentage } \\
(\%)\end{array}$ & Mean \pm SD \\
\hline \multirow[t]{4}{*}{ Age } & $0-4$ & 6 & 20.0 & \multirow{4}{*}{$\begin{array}{c}6.85 \pm 2.37 \\
\text { Years }\end{array}$} \\
\hline & $5-8$ & 18 & 60.0 & \\
\hline & $9-12$ & 6 & 20.0 & \\
\hline & Total & 30 & 100.0 & \\
\hline \multirow[t]{3}{*}{ Sex } & Male & 22 & 73.3 & \\
\hline & Female & 8 & 27.7 & \\
\hline & Total & 30 & 100.0 & \\
\hline \multirow[t]{3}{*}{ Side } & Left & 19 & 63.3 & \\
\hline & Right & 11 & 36.7 & \\
\hline & Total & 30 & 100.0 & \\
\hline \multirow[t]{5}{*}{ Causes } & Fall from tree & 15 & 50.0 & \\
\hline & Fall from bed & 6 & 20.0 & \\
\hline & Road traffic injury & 5 & 16.7 & \\
\hline & Fall during playing & 4 & 13.3 & \\
\hline & Total & 30 & 100.0 & \\
\hline
\end{tabular}

Table-II: Time interval between injury and operation.

\begin{tabular}{lccc}
\hline Time in interval in hours & Number of patient & Percentage $(\%)$ & Mean $( \pm$ SD) \\
\hline (0-6) hours & 1 & 3.3 & \\
(7-12) hours & 11 & 36.7 & $8.06 \pm 5.52$ \\
$(13-18)$ hours & 16 & 53.3 & Hours \\
$(19-24)$ hours & 2 & 6.7 & \\
Total & 30 & 100.0 & \\
\hline
\end{tabular}


Out of 30 patient's about $16(53.3 \%)$ of the patient's was operated between (13-18) hours of receiving injury, 11 (36.7\%) with in (7-12) hours and 1 (3.3\%) within (0-6) hours of injury and 2(6.7\%) with in (19-24) hours of injury, mean interval between injury and Operation was $8.06 \pm$ 5.52 hours.

Table-III: Distribution of the patients by loss of carrying angle according to Flynn's criteria $(n=30)$.

\begin{tabular}{lccc}
\hline $\begin{array}{l}\text { Loss of carrying } \\
\text { angle in degrees }\end{array}$ & Number of patient & Percentage (\%) & Mean $( \pm$ SD) \\
\hline No Loss & 3 & 10.0 & $8.5 \pm 5.61$ \\
$1-5$ & 4 & 13.3 & Degrees \\
$5-10$ & 17 & 56.7 & \\
$10-15$ & 3 & 10.0 & \\
$>15$ & 3 & 10.0 & \\
\hline
\end{tabular}

Among 30 Patient, mean loss of carrying angle was $8.5 \pm$ 5.61 degrees.

Table-IV: Distribution of the patients by loss of elbow flexion and carrying angle according to Flynn's criteria.

\begin{tabular}{|c|c|c|c|c|}
\hline & & $\begin{array}{l}\text { No of } \\
\text { Patient }\end{array}$ & $\begin{array}{c}\text { Percentage } \\
(\%)\end{array}$ & Mean \pm SD \\
\hline \multirow{6}{*}{$\begin{array}{l}\text { Loss of } \\
\text { range of } \\
\text { motion in } \\
\text { degrees }\end{array}$} & No Loss of flexion & 3 & 10.0 & \multirow{6}{*}{$\begin{array}{c}9.53 \pm 5.048 \\
\text { Degrees }\end{array}$} \\
\hline & $1-5$ & 3 & 10.0 & \\
\hline & $5-10$ & 18 & 60.0 & \\
\hline & $10-15$ & 3 & 10.0 & \\
\hline & $>15$ & 3 & 10.0 & \\
\hline & Total: & 30 & $100 \%$ & \\
\hline \multirow{6}{*}{$\begin{array}{l}\text { Loss of } \\
\text { carrying } \\
\text { angle in } \\
\text { degrees }\end{array}$} & No Loss & 3 & 10.0 & \multirow{6}{*}{$\begin{array}{l}8.5 \pm 5.61 \\
\text { Degrees }\end{array}$} \\
\hline & $1-5$ & 4 & 13.3 & \\
\hline & $5-10$ & 17 & 56.7 & \\
\hline & $10-15$ & 3 & 10.0 & \\
\hline & $>15$ & 3 & 10.0 & \\
\hline & Total: & 30 & $100 \%$ & \\
\hline
\end{tabular}

Table-V: Distribution of complications $(n=30)$.

\begin{tabular}{lcc}
\hline Complication & No. of Patients & Percentage (\%) \\
\hline Pin tract infection & 4 & 13.3 \\
Fracture blister & 4 & 13.3 \\
Median nerve palsy & 1 & 3.3 \\
Failure of fixation & 2 & 6.7 \\
Volkmann's Ischemia & 0 & 0 \\
Radial nerve palsy & 0 & 0 \\
Ulnar nerve palsy & 0 & 0 \\
No complications & 19 & 63.3 \\
\hline
\end{tabular}

In this series $4(13.3 \%)$ patients out of 30 cases developed pin tract infection, $4(13.3 \%)$ patients out of 30 cases were developed fracture blister. All are superficial infection and culture shown staphylococcal infection, according to sensitivity, antibiotic was given and cured. In this series $1 \%$ (3.3\%) patient's median nerve palsy and $2(6.7 \%)$ patients had inadequate pin fixation first attempt. The pins had to removed and refixed after second reduction.
Table-VI: Shows loss of motion and carrying angle in different groups of functional outcome.

\begin{tabular}{lccc}
\hline $\begin{array}{l}\text { Loss of motion } \\
\text { in degree }\end{array}$ & $\begin{array}{c}\text { Loss of carrying } \\
\text { angle in degree }\end{array}$ & Grading & Percent (\%) \\
\hline $0-5$ & $0-5$ & Excellent (6) & 20.0 \\
$5-10$ & $5-10$ & Good (18) & 60.0 \\
$10-15$ & $10-15$ & Fair (3) & 10.0 \\
$>15$ & $>15$ & Poor (3) & 10.0 \\
\hline
\end{tabular}

Functional outcome was analyzed by Flynn's grading. In this study, all 30 patients were treated by closed reduction and percutaneous K-wire fixation. $6(20 \%)$ out of 30 were provided excellent results, $18(60 \%)$ out of 30 cases shown good results and $3(10 \%)$ out of 30 fair outcome and 3 $(10 \%)$ out of 30 cases poor outcome.

Table-VII: Final outcome according to Flynn Criteria.

\begin{tabular}{lllll}
\hline \multirow{2}{*}{$\begin{array}{l}\text { No. of } \\
\text { Cases }\end{array}$} & \multicolumn{4}{c}{ Grading } \\
\cline { 2 - 5 } & Excellent & Good & Fair & Poor \\
& Number (\%) & Number (\%) & Number (\%) & Number (\%) \\
\hline 30 & $6(20.0)$ & $18(60.0)$ & $3(10.0)$ & $3(10.0)$ \\
\hline
\end{tabular}

Final Outcome was analyzed by Flynn's grading. In this study there were $6(20.0 \%)$ cases with excellent, $18(60.0 \%)$ were good and $3(10.0 \%)$ were fair and $3(10.0 \%)$ were poor functional outcome.

Table-VIII: Distribution of the patients by radiological outcome and functional outcome $(n=30)$.

\begin{tabular}{|c|c|c|c|}
\hline & Results & No. of patients & Percentage (\%) \\
\hline \multirow{3}{*}{$\begin{array}{l}\text { Radiological } \\
\text { outcome }\end{array}$} & Sufficient callus formation & 27 & 90 \\
\hline & No sufficient callus formation & 03 & 10 \\
\hline & Total & 30 & 100 \\
\hline \multirow{3}{*}{$\begin{array}{l}\text { Functional } \\
\text { outcome }\end{array}$} & Satisfactory & 27 & 90 \\
\hline & Unsatisfactory & 03 & 10 \\
\hline & Total & 30 & 100 \\
\hline
\end{tabular}

In this series, among 30 Patients, 27(90.0\%) had radiologically sufficient callus formation and $3(10.0 \%)$ patients had no sufficient callus formation. Functional outcomewassatisfactory result (Excellent, Good and Fair) were 27(90.0\%) and unsatisfactory result (poor) was $3(10.0 \%)$.

\section{Discussion:}

In this series, sample sizes was 30 the fracture was found more common in boys $22(73.3 \%)$ than girls $8(27.7 \%)$. In other series of supracondylar fracture, there was a higher frequency in male patients $70 \%$, female $30 \%$, sample size was $20^{9}$.

In this study mean age of the patients were $6.85 \pm 2.37$ years. In other series of supracondylar fracture, mean age of $6.1 \pm 3.07$ years $^{10}$.

In this study, left side was more involved in 19 (63.3\%) of patients. While right side fracture was $11(36.7 \%)$. In other series of supercondylar fracture, left side $(60.24 \%)$, right side $(39.76 \%)^{11}$.

In this studies most common cause of supracondylar fracture was due to fall from tree $50 \%$, fall from bed $20 \%$, 
road traffic injury $16.7 \%$, fall during playing $13 \%$. Other series of supercondylar fracture most common cause fall from height $46.66 \%$, fall from bed $6.66 \%$, fall during playing $20 \%$, fall due to RTA $26.68 \%{ }^{12}$. In this study, among 30 Patient, there are $27(90.0 \%)$ radiologically sufficient callus formation and $3(10.0 \%)$ patients had no sufficient callus formation. In radiological union- 3 out of 4 cortices with bridging callus ${ }^{13}$. In this study, the loss of flexion of elbow, $10 \%$ no loss of flexion, $10 \%$ show's loss of flexion of elbow was (1-5) degrees, $60 \%$ shows loss of flexion of elbow was (6-10) degrees and $20 \%$ shows loss of flexion of elbow was (11-15) degrees, mean loss of flexion of elbow was 9.53 \pm 5.048 degrees.In other series; Anowar et al. 2011, the mean loss of elbow flexion were $8.38^{\circ} \pm 3.10$ degrees, Foead et al. the loss of elbow flexion were $8.68^{\circ}$ in medial-lateral pin fixation, the loss of elbow flexion were $11.26^{\circ}$ in two lateral pin fixation ${ }^{14}$. Percutaneous lateral parallel $\mathrm{K}$-wire fixation can solve the problem. It requires general anaesthesia, aseptic precaution, C-arm followed by antibiotic therapy. Percutaneous pin can be fixed through lateral condyle. Though stability of fixation incase of medial-lateral pin fixation is biomechanically more than lateral pin fixation but there is more chance of unlar nerve injury in medial K-wire fixation. This problem can be solved by only lateral pin fixation.We think that the treatment of Gartland type-III closed supracondylar fracture of the humerus in children with only a lateral $\mathrm{K}$-wire would be safer and more convenient ${ }^{15}$. In this series patient usually presented with a range of 2 hours to 24 hours, average delay at presentation was 8.06 hours. In other series of supercondylar fracture patient usually presented with a range of $1 / 2$ an hour to 72 hours, average delay of more than 12 hours in presentation ${ }^{16}$. In this series patient usually presented with a range of 2 hours to 24 hours, average delay at presentation was 8.06 hours. In other series of supercondylar fracture a delay of more than 12 hours in presentation ${ }^{17}$. In this study, mean loss of carrying angle was $8.5 \pm 5.61$ degrees. Vaidya (2009) showed in group A (Lateral pin fixation) mean loss of carrying angle was $3.70^{\circ}$ and In group B (both side pin fixation) mean loss of carrying angle was $3.57^{\circ} 18$. In this study mean age of the patients were $6.85 \pm 2.37$ years. In other series of supracondylar fracture, mean age of 5.8 years ${ }^{19}$. In this study, the loss of flexion of elbow, $10 \%$ no loss of flexion, $10 \%$ show's loss of flexion of elbow was (1-5) degrees, $60 \%$ shows loss of flexion of elbow was (6-10) degrees and $20 \%$ shows loss of flexion of elbow was (11-15) degrees, mean loss of flexion of elbow was $9.53 \pm 5.048$ degrees. In other series; Foead et al. the loss of elbow flexion were $8.68^{\circ}$ in medial-lateral pin fixation, the loss of elbow flexion were $11.26^{\circ}$ in two lateral pin fixation ${ }^{20}$. In this study, $1(3.33 \%)$ patient had medial nerve palsy, pin tract infection $4(13.33 \%)$, fracture blister $4(13.34 \%)$, failure of fixation $2(6.67 \%), 2$ patients had inadequate pin fixation at first attempt, which did not get contact with the proximal fragment. In other series, cited an incidence of $18 \%$ vascular and $8 \%$ neural complications in his 72 displaced supracondylar fracture study ${ }^{2}$. In this study, Final outcome of our study, $6(20.0 \%)$ cases were excellent, $18(60 \%)$ were good and $3(10 \%)$ were fair and $3(10 \%)$ had poor result among 30 cases. The overall satisfactory result (including the excellent, good and fair) was 90\%. In other series of supracondylar fracture, Flynn et al. (1974) achieved 98\% satisfactory results. Good functional and cosmetic outcome is our goal. For this closed reduction and stabilization by two lateral parallel percutaneous K-wire is a better option.

\section{Conclusion:}

There are several methods of treatment of this fracture, closed reduction and percutaneous lateral $\mathrm{K}$ wire pinning through lateral epicondyle provides good stabilization with less chance of iatrogenic nerve injury, less complications, no fracture re-displacement, no post-operative deformity and almost quite normal functional outcome.

\section{Conflict of Interest: None.}

\section{Acknowledgement:}

Thanks and all praise to Almighty Allah, the beneficent, the merciful for providing us enough energy and patience to complete this article. Our special thanks and gratitude to Prof. Dr. Md. Shah Alam, National Institute of Traumatology and Orthopedic Rehabilitation (NITOR), Dhaka, Bangladesh.Prof. Dr. Shaymol Chandra Dabnath, National Institute of Traumatology and Orthopedic Rehabilitation (NITOR), Dhaka, Bangladesh for providing instructions, encouragement and valuable advice from beginning of this study. We should like express our sincere gratitude and grateful to all Teachers, Doctors and Employee in the department of Orthopedics National Institute of Traumatology and Orthopedic Rehabilitation (NITOR), Dhaka, Bangladesh for valuable suggestion and advice to complete this study.

\section{References:}

1. Lal K, Chachar MB, Chohan MH, Baig MA, Khoso JA. Gartland type III supracondylar fracture humerus; surgical management. Professional Medical Journal. 2015; 22:1629-33.

\section{https://doi.org/10.17957/TPMJ/15.3133}

2. Flynn JC, Matthews JG, Benoit RL, Florida O. Blind pinning of supracondylar fractures of the humerus in children. The Journal of Bone and Joint Surgery. 1974 March; 56(2): 263-72.

\section{https://doi.org/10.2106/00004623-197456020-00004}

3. Chen, RS, Liu CB, Lin XS, Feng XM, Zhu JM. Supracondylar extension fracture of the numerous in children. Manipulative reduction, immo $\mathrm{n}$ bilization and fixation use in a U-shaped plaster slab with the elbow in full extension. Journal of Bone and joint Surgery. 2001: 83:883-86.

https://doi.org/10.1302/0301-620X.83B6.0830883

4. George PT, Kattoor MJ, Edayalamuriyil SS. Treatment outcome of gartland type III Supracondylar fractures of the Humerus in children with closed reduction and 
percutaneous pinning. International Journal of Research in Orthopaedics. 2016; 2: 95-98.

https://doi.org/10.18203/issn.2455-4510.IntJResOrthop20162782

5. Elbahri, H. M. H., Ahmed, I. S., Bashir, E.S., Gashi, Y.N., et al. Auditing the use of percutaneous pinning as a technique of fixation of unstable humeral supracondylar fractures in Sudanese children. Sudan Journal of Medical Sciences. 2010; 5:265-70.

https://doi.org/10.4314/sjms.v5i4.64495

6. Kinkpe, C.V.A., Dansokho, A.V., Niane, M.M., et al. Children distal humerus supracondylar fractures: The Blount Method experience. Orthopaedics \& Traumatology: Surgery \& Research. 2010; 96:276-82.

https://doi.org/10.1016/j.otsr.2009.12.010

PMid:20488147

7. Piggot, J., Graham, H. K., McCoy, G. 1986. Supracondylar fractures of the Humerus in children. The Journal of Bone and Joint Surgery. 1986; 68:577-83.

https://doi.org/10.1302/0301-620X.68B4.3733834

PMid:3733834

8. Devkota, P., Khan, J. A., Acharya, B. M. 2008. Outcome of Supracondylar Fractures of the Humerus in Children Treated by Closed Reduction and Percutaneous pinning. Journal of Nepal Medical Associatio. 2008; 47:66-70.

https://doi.org/10.31729/jnma.314

9. Shoaib M, Sultan S, Sahibzada SA, Ali A. Percutaneous pinning in displaced supracondylar fracture of the humerus in children. Viewed 7 May 2012, <http//www.ayubmed.ed u.pk/JAMC/ PAST/16-4/Shoaib.htm.

10. El-Adl WA, El-Said MA, Boghdady GW, Ali ASM. 2008. Results of treatment of displaced supracondylar humeral fractures in children by percutaneous lateral cross-wiring technique. Start Trauma Limb Recon. 2008; 3:1-7.

https://doi.org/10.1007/s11751-008-0030-3

PMid:18427917 PMCid:PMC2291475

11. Bulbul M, Ayanoglu S, Imren Y, Kahraman S, Esenyel CZ, Gurbuz H. Does Two Parallel Lateral- Only Pin Configuration Provide Stable Osteosynthesis for Pediatric Supracondylar Humerus Fractures. Nobel Medicus. 2011; $7: 36-40$

12. Sarwar G. Management of early supracondylar fracture of the Humerus in children treated by open reduction and internal fixation by K-wire. Thesis (MS), National Institute of Traumatology and Orthopaedic Rehabilitation (NITOR) under University of Dhaka for Master of Surgery; 2003.

13. Horwitz D, Archdeacon M, Crist BT. Basic Principles and Techniques of Internal Fixation of Fractures. OTA Resident Course Presentation, slide no. 2; 2009.

14. Anwar, W., Rahman, N., Iqbal, M. J., et al. Comparison of the two methodsof Percutaneous K-wire Fixation in Displaced Supracondylar fractures of humerus in children. Journal of Postgraduate Medical Institute. 2011; 25:356-61.

15. Belhan, O., Karakurt, L., Ozdemir, H., et al. Dynamics of the ulnar nerve atfter percutaneous pinning of supracondylar humerus fractures in children.Journal of Pediatric Orthopaedics. 2009;18: 29-33.

https://doi.org/10.1097/BPB.0b013e32831960fa

PMid:19002068

16. De Gheldere A, Bellan D. Outcome of Gartland type II and type III supracondylar fractures treated by Blount's technique. Indian Journal of Orthopaedics. 2010; 44:89-94.

https://doi.org/10.4103/0019-5413.58612

PMid:20165683 PMCid:PMC2822426

17. Dua A, Eachempati KK, Malhotra R, Sharma L, Gidaganti $\mathrm{M}$. Closed reduction and percutaneous pinning of displaced supracondylar fractures of humerus in children with delayed presentation. Chinese Journal of Traumatology. 2011; 14:14-19.

18. Vaida. S.M. Percutaneous fixation of displaced supracondylar fracture in children comparing lateral with medial and medial and lateral pin. Thesis(M.Ch.) (Orthopedics), University of Seychelles, American institute of medicine; 2009.

19. Edmonds, E. W., Roocroft, J. H., Mubarak, S. J. 2012. Treatment of Displaced

Pediatric Supracondylar Humerus Fracture Patterns Requiring Medical Fixation:

A Reliable and Safer Cross-pinning Technique. Journal of Pediatric

Orthopaedics. 2012; 32:346-51.

https://doi.org/10.1097/BPO.0b013e318255e3b1

PMid:22584833

20. Pirone, A.M., Graham, H. K.., Karjbich, J. I. 1988. Management of displaced extension-type Supracondylar fractures of the humeurs in children. Journal of Bone and Joint Surgery. 1988; 70:641-49.

https://doi.org/10.2106/00004623-198870050-00002 